\title{
VOLTAGE SAG COMPENSATION USING DISTRIBUTION STATIC COMPENSATOR (DSTATCOM)
}

\author{
Priyanga Shalini, \\ Department of Electrical and Electronics Engineering, \\ Bharathiyar College of engineering and technology, \\ Karaikal, India. \\ thamaraimalar888@gmail.com \\ Keerthivasan M, \\ Department of Electrical and Electronics Engineering, \\ Bharathiyar College of engineering and technology, \\ Karaikal, India. \\ krtivsn.er@gmail.com \\ Suresh Padmanabhan T, \\ Department of Electrical and Electronics Engineering, \\ Bharathiyar College of engineering and technology, \\ Karaikal, India. \\ sureshsilver@gmail.com
}

\begin{abstract}
Distribution Static compensator (D-STATCOM) is employed to solve the sag problems in this paper. In order to operate a four wire DSTATCOM in voltage control mode, it requires a reference voltage. To generate the required reference voltage, a new schematic algorithm is developed. It ensures Unity Power Factor (UPF) at different load and fault conditions, which is not possible in conventional scheme. Also, the shunt active filter injects lower current which reduces losses in the feeder and VSI. Furthermore, the power saving capacity of DSTATCOM mitigates the voltage sag. As the voltage is regulated at different load condition, UPF is maintained. The power quality issues are tackled by correcting the power factor, eliminating the harmonic distortion, balancing the load and regulating the voltage based on the load requirement.
\end{abstract}

Keywords: Voltage Sag Characteristic, Faults, Unity Power Factor, Voltage Control Mode, Power Quality, Voltage Source Inverter, DSTATCOM.

\section{INTRODUCTION}

The distribution power system suffers many power quality problems such as flickers, voltage deviation during load changes, under voltage (sag) over voltage (swell) and voltage transients, harmonics and dc offset etc [1]. The usage of unbalanced load and poor power factor based loads are the main reason for these kinds of PQ problems [2] [3]. Therefore this issue has totally affected the consumer loads and also overheating occurred in intermediate transformers. In the past, the LC filters are proposed to mitigate the problems. But this type of passive filter have some limitations; the filters are working depends on time and fixed compensation only possible. Therefore, the Flexible AC Transmission System (FACT) devices are introduced to eliminate the sag and swell type of power quality problems. It can be constructed by power semiconductor devices such as Active Power Line Conditioners (APLC's) or Active Power Filters (ACF) [4].

DSTATCOM is the most famous shunt active filter in distribution line among the other power devices. DSTATCOM is very simple construction is shown in Figure 1(a) and can provide an effective solution in fault time and obtained the 
efficient compensation of load unbalancing and reactive power in the distribution system.

The operation of DSTATCOM is similar to STATCOM. The control of reactive power flow depends on the ratio of magnitudes of the actual RMS voltages. The DC link voltage acts as a storage element which maintains power ratings, controlling the harmonics using resonant elements. The active power flow is controlled by the following factors; DC link fed VSC voltages and angle between the AC systems. The DSTATCOM follows the load currents and voltages continuously in order to find the required amount of compensation by the AC system $[6,7]$.

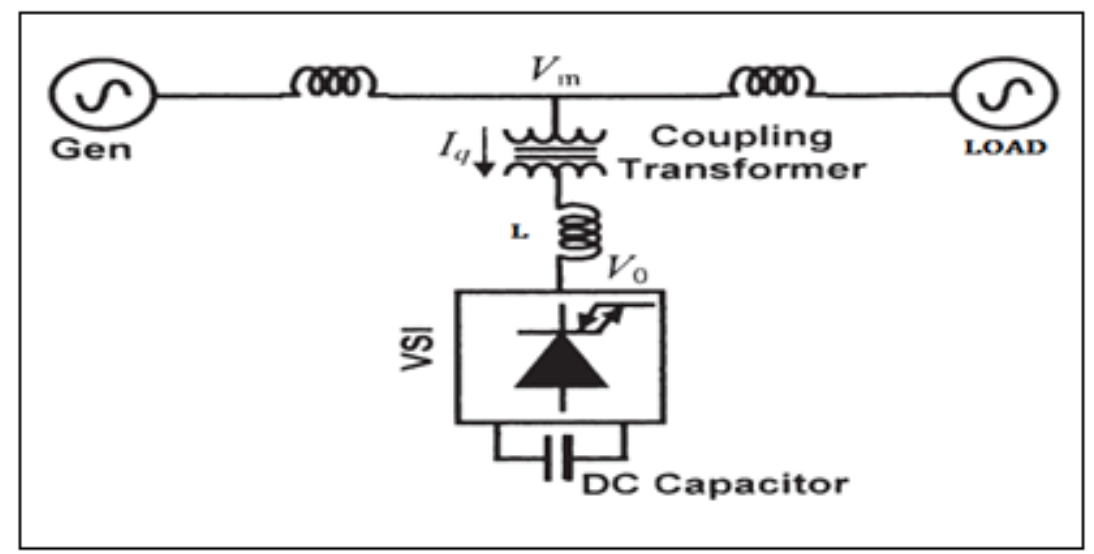

Fig. 1(a) General DSTATCOM scheme

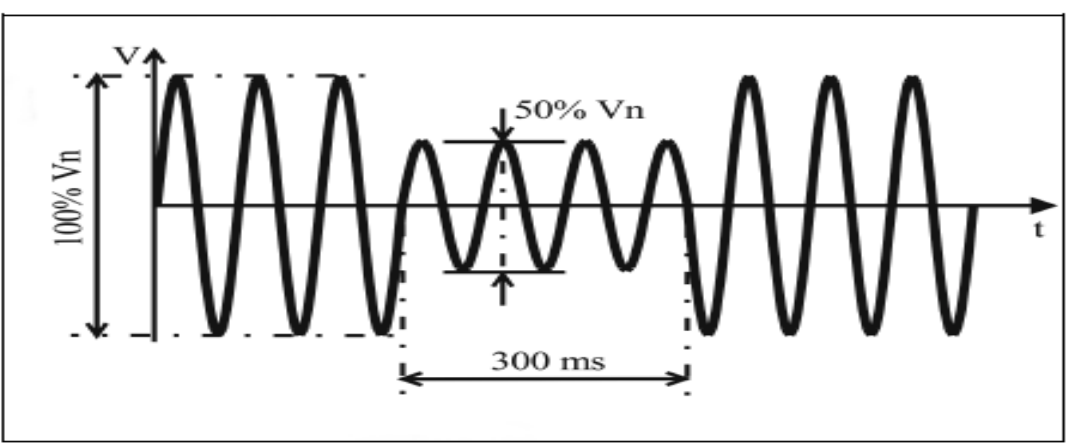

Fig. 1(b) Voltage sag condition

Voltage sag is one of the power quality problems [5]. Since voltage sag has able to tripping of equipment at the result; totally stop the power distribution process which tends to affects financial of the system. A vast literature showed that voltage sag is the worst interruptions in the power system. Voltage sag in distribution line is shown in Figure 1(b). The sag characteristic depends on the sag magnitudes and its phase-angle jump, duration of magnitude reduction, the under voltage condition has classified by Location of fault (unbalanced voltage in different load condition); X/R ratio of the line fault (Single phase/Double phase/three phase to line fault in transmission line. Therefore this paper is focused to compensate the various types of sag problems using three phase four 
wire DSTATCOM [8]. The main aim of the paper is the correction of UPF at fault and various fault conditions.

\section{PROPOSED SCHEME}

The proposed shunt active filter (DSTATCOM) is interfaced between the source and load end using Point of Common Coupling (PCC) [9]. It has operated in two basic modes; Current Control Mode (CCM) and Voltage Control Mode (VCM). In $\mathrm{CCM}$, reactive power has injected in load components to PCC whereas PCC voltage is regulated in VCM at a reference voltage and protects the faults. In conventional system, PCC voltage is regulated at 1.0 per unit (p.u.) However, load operates under different voltage range [10][11].

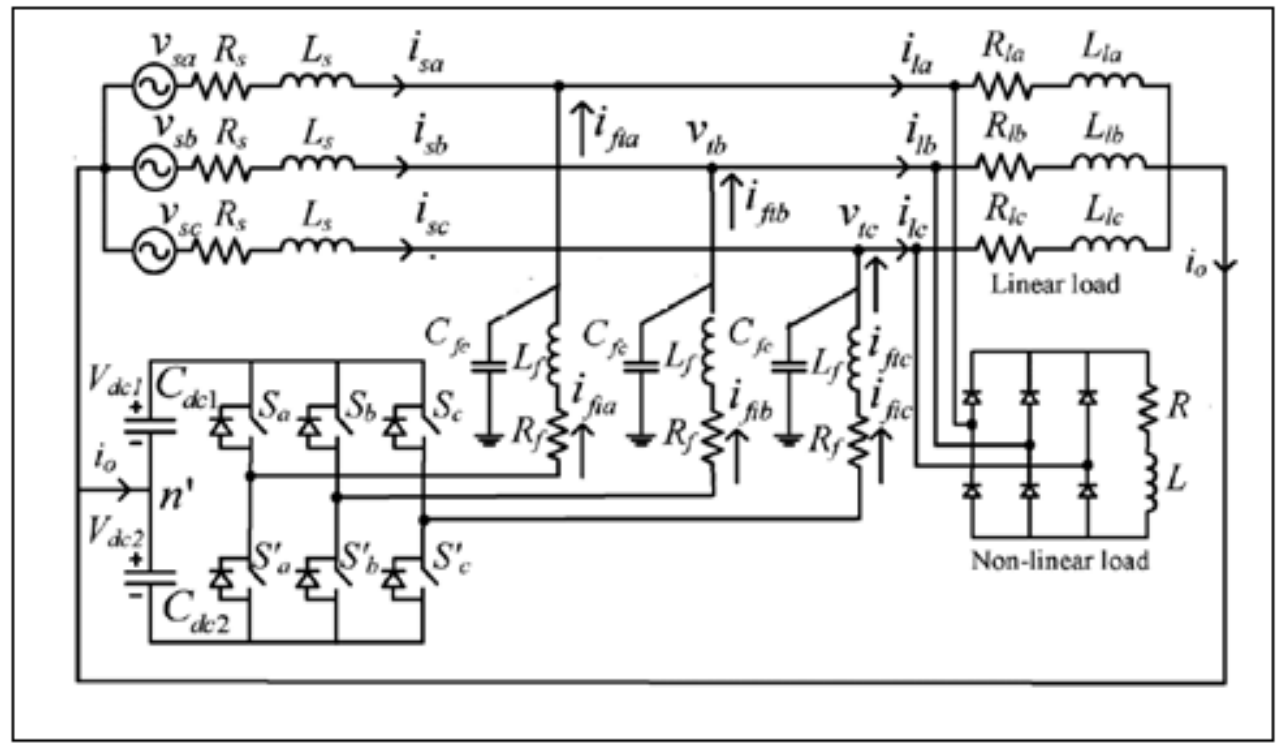

Fig. 2 Voltage sag condition

Figure 2 shows the proposed circuit arrangement. The overall circuit structure has considered a two-level, four-wire, three-phase and neutral point clamped VSI. The shunt active filter is connected with PCC help of Filter inductance and capacitance respectively. The high-switching frequency components are eliminated by shunt capacitor [12]. The VSI component specifications are selected by depends on the PCC voltage regulation. Then, Proportional-Integral (PI) controller is used to control the VSI with hysteresis loop, which regulates the DC capacitor voltage.

\section{CONTROLLER FOR DC BUS CAPACITOR}

Figure 3 shows the overall controller scheme. Based on the following parameters; change in DC bus voltage, a period of sag at various load, the DC capacitors values are properly selected. Let us consider the total load rating is $\mathrm{S}$ $\mathrm{kVA}$ [13]. The load power varies from 0 to $\mathrm{S} \mathrm{kVA}$. To maintain load power, the compensator exchanges the active power during transient state [14]. 


$$
\frac{1}{2} \mathrm{C}_{\mathrm{dc}}\left(\mathrm{V}_{\mathrm{dcref}}^{2}-\mathrm{V}_{\mathrm{dc}}\right)=\mathrm{PST}
$$

where $\mathrm{P}$ is a number of cycles; $\mathrm{T}$ is the time period of the system.

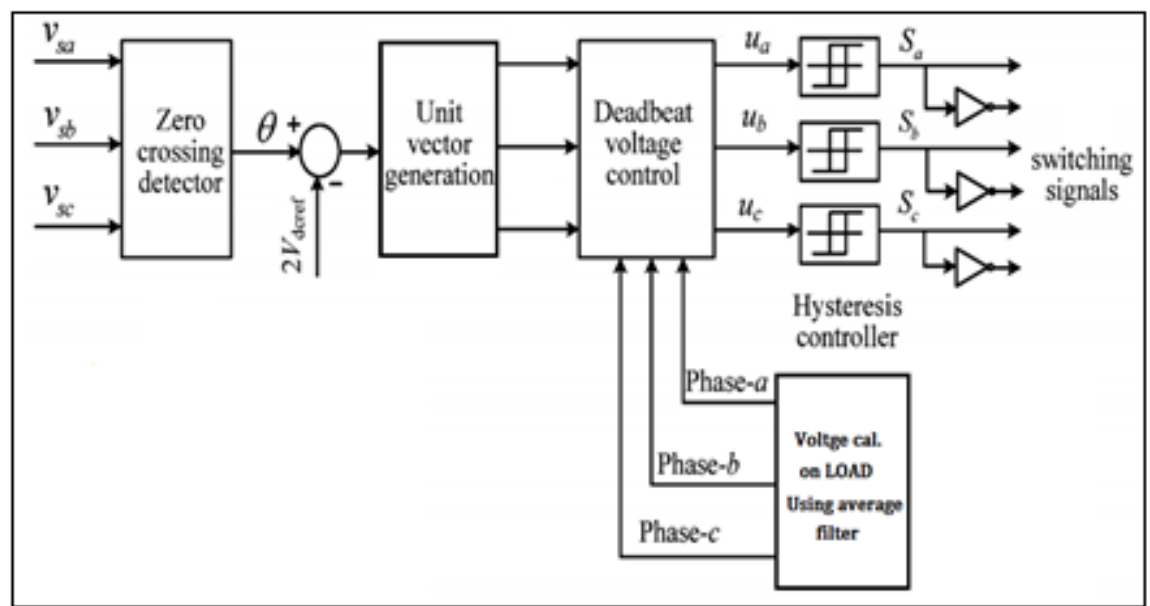

Fig. 3 Controller scheme

Reference terminal voltages are obtained from the source $\left(v_{s a}, v_{s b}, v_{s c}\right)$ and nominal load ends (phase a, b, c) respectively. At first, the load currents in the positive sequence components are monitored, and they are considered as the reference at nominal load with the assumption that they come from the source. Hysteresis controller can provide the desired switching signals VSI filter.

\section{SIMULATION RESULT}

The proposed VCM based DSTATCOM system is employed to mitigate the power quality problem. Different type of fault conditions (load unbalance, phaseground fault) has been tested using MATLAB/Simulink. It can compensate voltage sag of more than $50 \%$ at nominal voltage. Table 1 shows the component specifications of DSTATCOM. 


\section{TABLE 1 Component specifications of DSTATCOM}

\begin{tabular}{|c|c|}
\hline System quantities & Values \\
\hline Feeder impedance & $Z_{\mathrm{s}=1+\mathrm{j} 3.14 \Omega}$ \\
\hline Linear load & $\begin{array}{c}Z_{l a}=30+\mathrm{j} 62.8 \Omega, \\
Z_{l b}=40+\mathrm{j} 78.8 \Omega \\
Z_{l c}=50+\mathrm{j} 52.24 \Omega\end{array}$ \\
\hline & $400 \mathrm{~V} \mathrm{rms} \mathrm{line} \mathrm{to} \mathrm{line}$ \\
& $50 \mathrm{~Hz}$ \\
\hline Source voltage & $50+\mathrm{j} 63.8 \Omega$ \\
\hline Non-linear load & $K_{P}=8.5, K_{I}=1.8$ \\
\hline PI gains & $1 \mathrm{v}$ \\
\hline Hysteresis band $(\mathrm{h})$ & \\
\hline
\end{tabular}

Sag can be classified into unbalanced or balanced based on the type of fault. To study the fault, they are created at a distance of $20 \%$ to $40 \%$ of its complete length in the line. The proposed system is tested on these faults to compensate them. Figures 4 to 14 show the outputs and performances of the system.

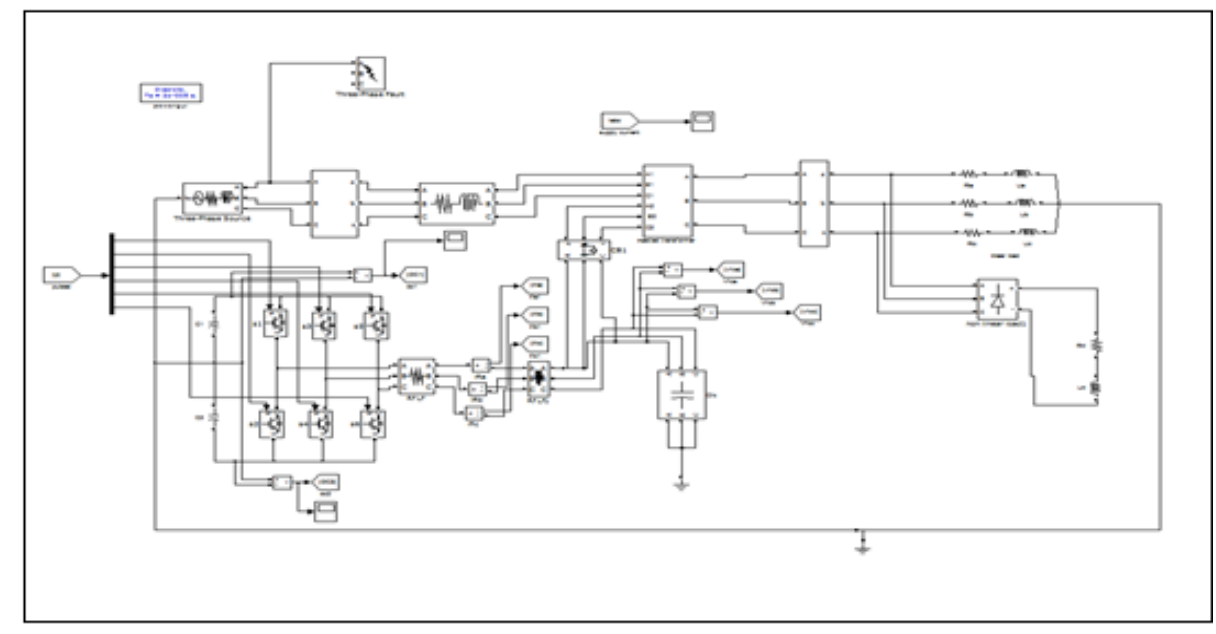

Fig. 4 Simulation circuit: single phase fault 


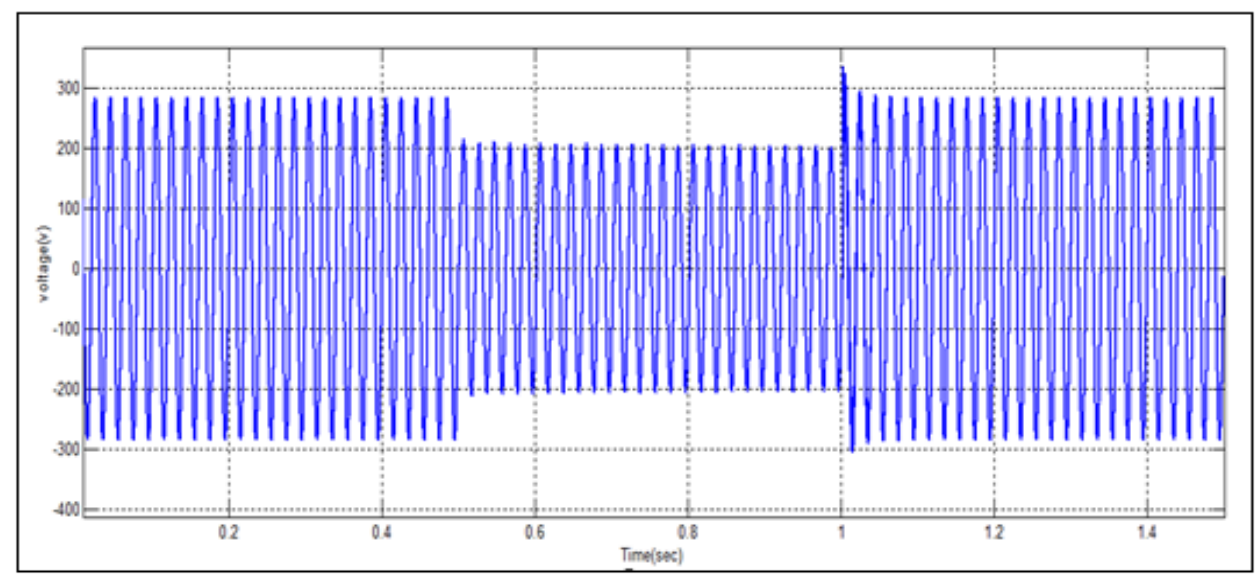

Fig. 5 Single phase sag voltage condition: $T: 0.5 \mathrm{~s}-1 \mathrm{sec}$

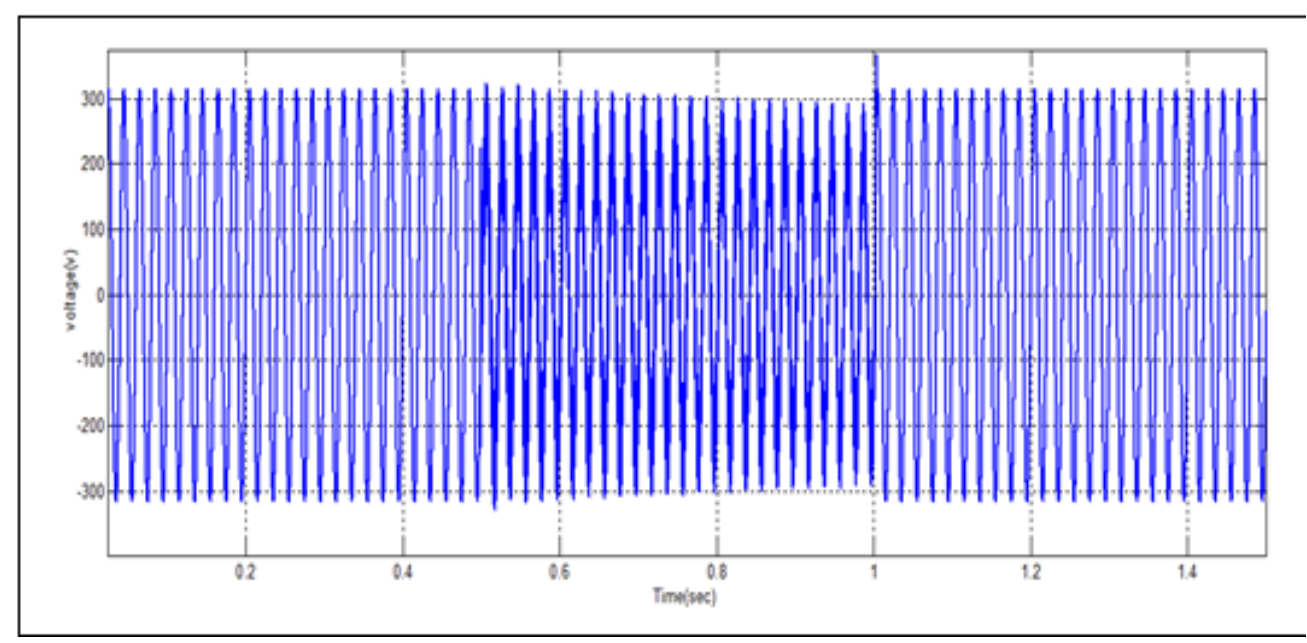

Fig. 6 Compensated sag voltage 


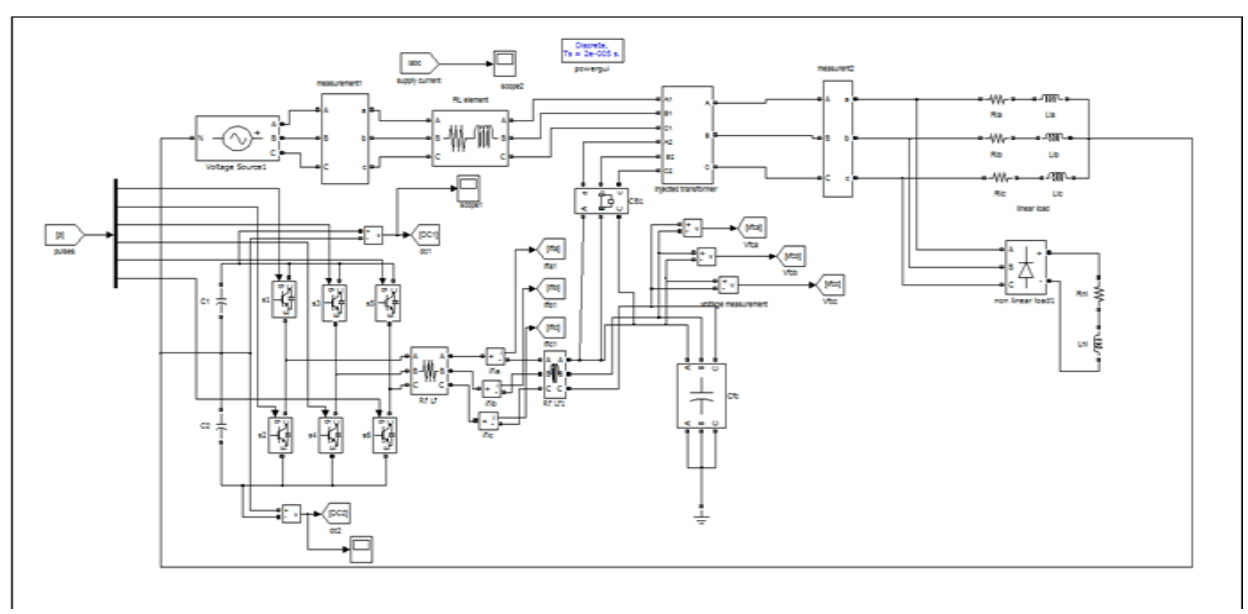

Fig. 7 Simulation circuit: phase magnitude fault

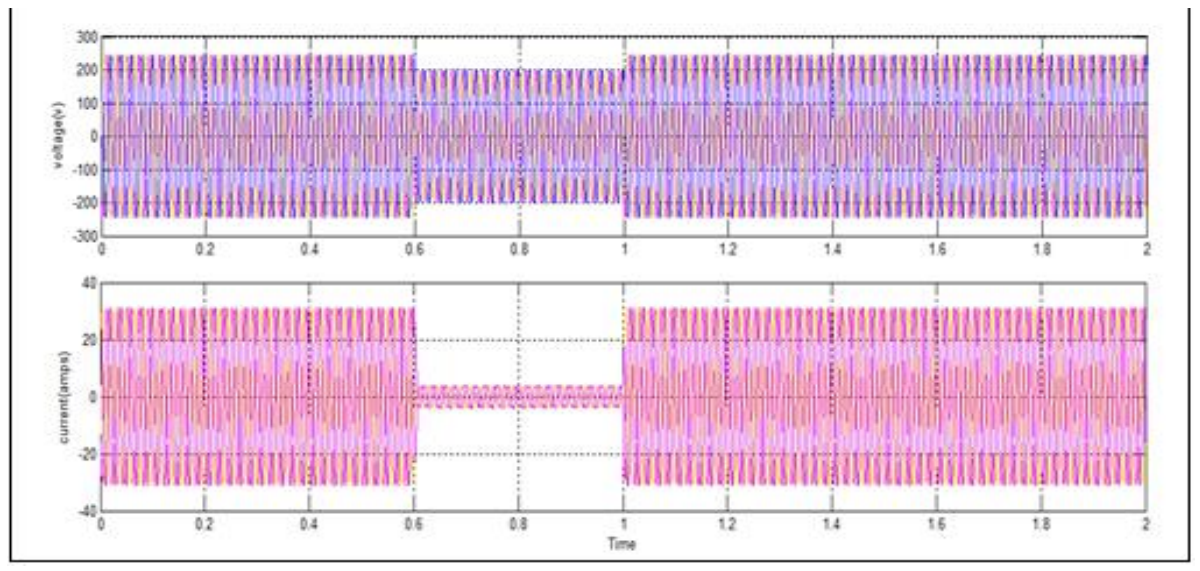

Fig. 8 Three phase sag voltage condition: T: $0.5 \mathrm{~s}-1 \mathrm{sec}$

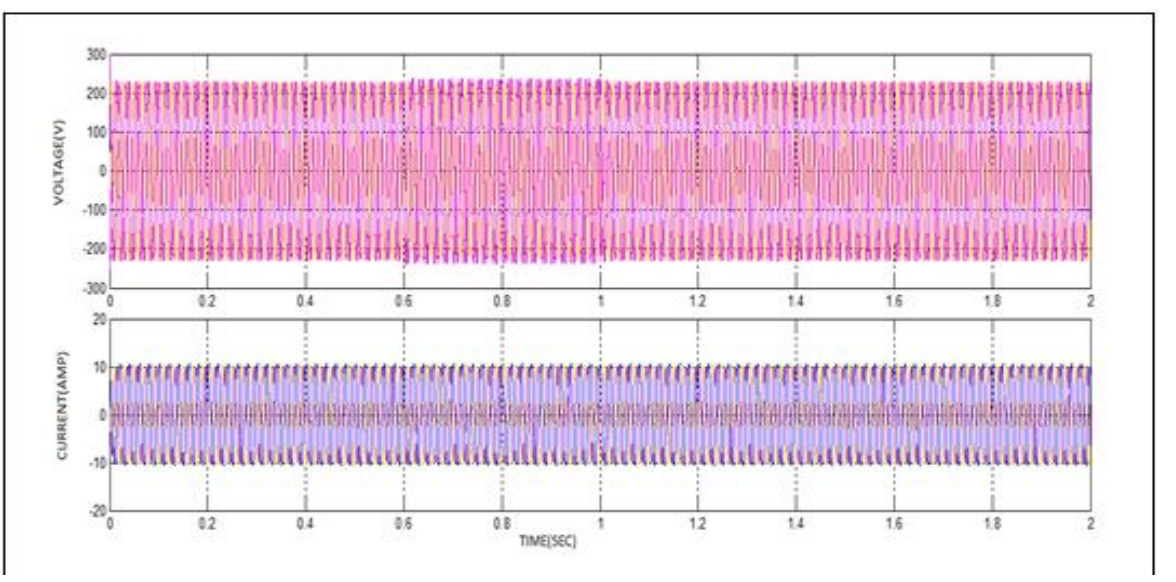

Fig. 9 Three phase compensated sag voltage 


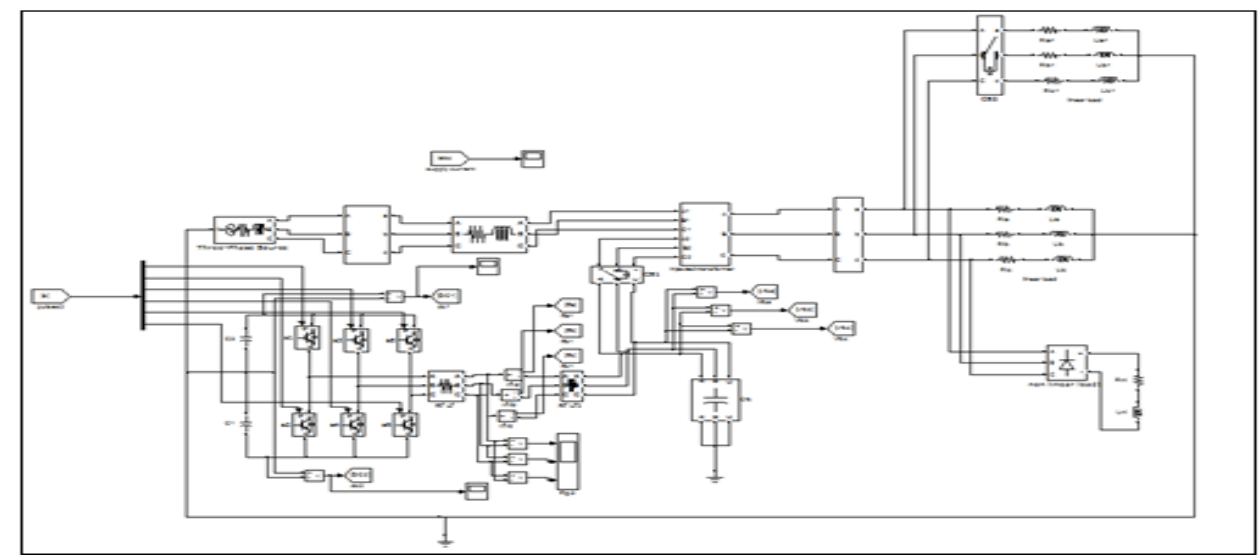

Fig. 10 simulation circuit: unbalancing load condition

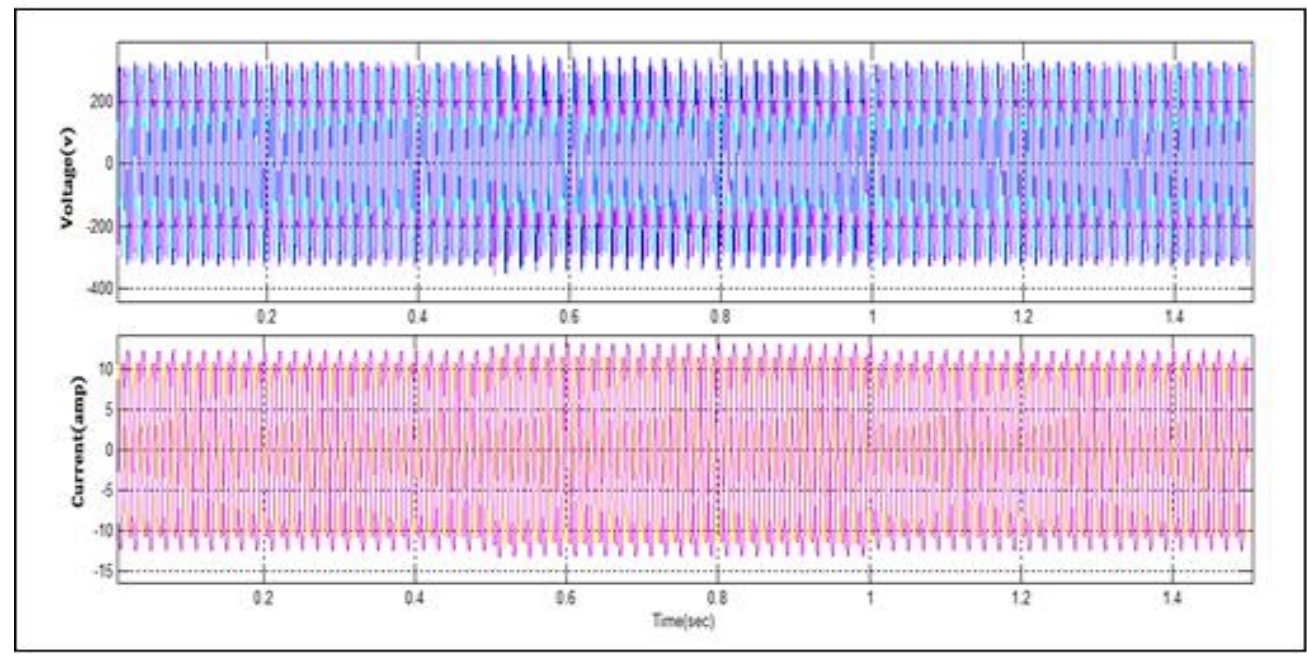

Fig. 11 unbalanced load voltage compensation

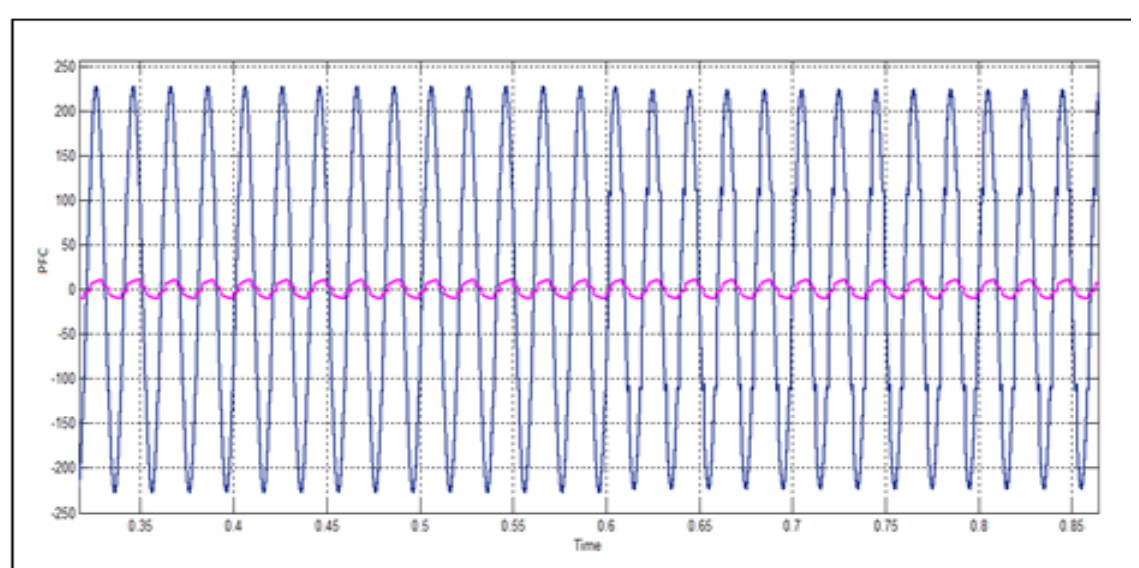

Fig. 12 Power Factor Correction (PFC) 


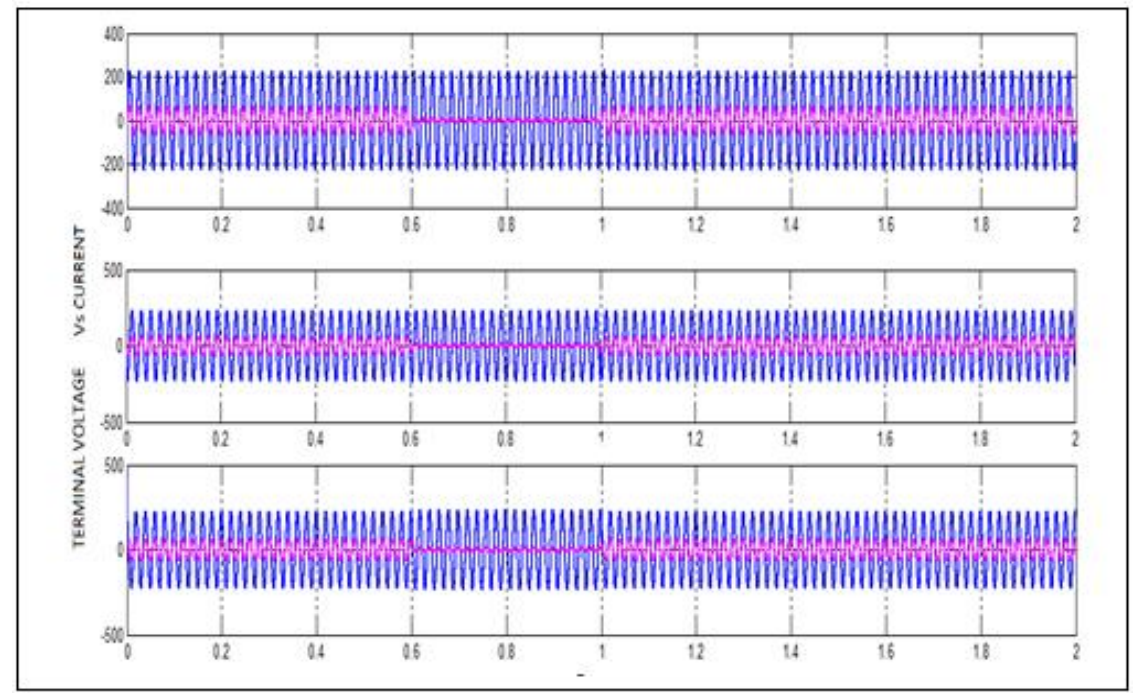

Fig. 13 Three phase Voltage \&current PFC

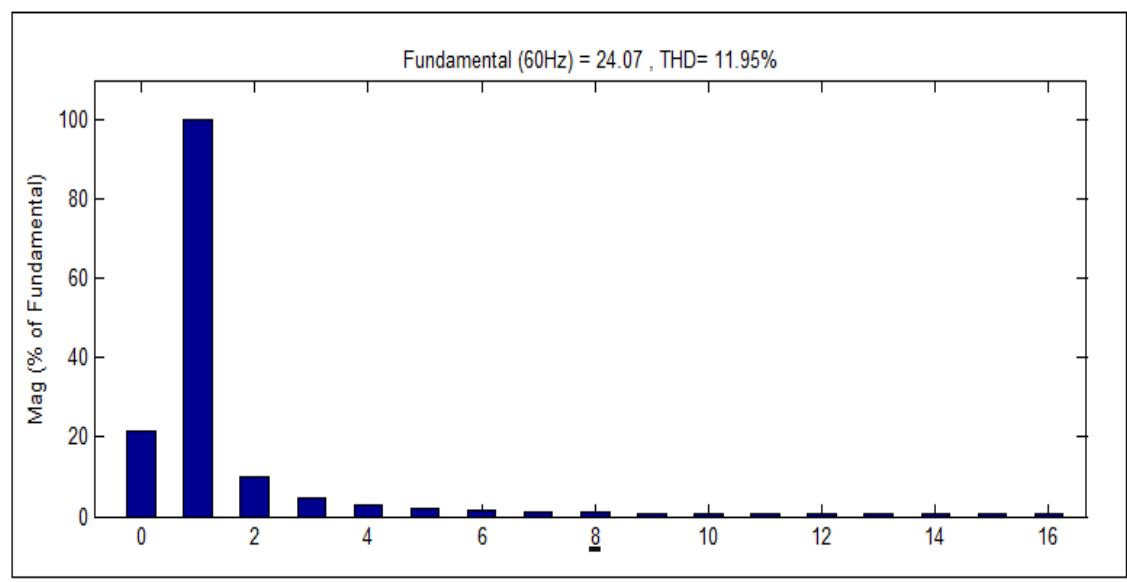

Fig. 14 Total Harmonic Distortion (THD)

\section{CONCLUSION}

In this paper, the voltage sag problem is avoided using Distribution Static compensator (D-STATCOM). This method follows a schematic algorithm to produce a reference voltage to operate the four-wire DSTATCOM in VCM. It ensures UPF at different load and fault conditions, which is not possible in the conventional scheme. Also, the shunt active filter injects lower current so that the losses in the feeder and VSI are reduced. Results show that $20 \%$ voltage sage is eliminated at the distribution end. The algorithm is implemented and tested using MATLAB/Simulink. 


\section{REFERENCES}

[1]. M. Bollen, "Understanding Power Quality Problems", IEEE Piscataway, Vol. 3, NJ, USA, 2005, pp. 1-35.

[2]. H. Fujita, and H. Akagi, "Voltage-regulation performance of a shunt active filter intended for installation on a power distribution system", IEEE Transaction on Power Electron, Vol. 22, No. 3, 2007, pp. 1046-1053.

[3]. M.H.J. Bollen, "Understanding Power Quality Problems: Voltage Sags and Interruptions", IEEE Press Series on Power Engineering, Piscataway, NJ, 2000, pp. 35-40.

[4]. M.N. Moschakis, and N.D. Hatziargyriou, "Analytical calculation and stochastic assessment of voltage sags", IEEE Transactions on Power Delivery, Vol. 21, No. 3, 2006, pp. 1727-1734.

[5]. H.V.D.C. Manitoba, Research centre, PSCAD/EMTDC: Electromagnetic transients program including dc systems, 1994.

[6]. M.K. Mishra, and K. Karthikeyan, "A fast-acting dc-link voltage controller for three-phase DSTATCOM to compensate ac and dc loads", IEEE Transaction on Power Delivery, Vol. 24, No. 4, 2009, pp. 2291-2299.

[7]. M.K. Mishra, A. Ghosh, A. Joshi, and H.M. Suryawanshi, "A novel method of load compensation under unbalanced and distorted voltages," IEEE Transaction on Power Delivery, Vol. 22, No. 1, 2007, pp. 288-295.

[8]. M. K.Mishra, A. Ghosh, and A. Joshi, "Operation of a DSTATCOM in voltage control mode", IEEE Transaction on Power Delivery, Vol. 18, No. 1, 2003, pp. 258-264.

[9]. J. Rodriguez, J. Pontt, C.A. Silva, P. Correa, P. Lezana, P. Cortes, and U. Ammann, "Predictive current control of a voltage source inverter," IEEE Transactions on Industrial Electronics, Vol. 54, No. 1, 2007, pp. 495-503.

[10]. M. Moradlou, and H. Karshenas, "Design strategy for optimum rating selection of interline DVR", IEEE Transaction on Power Delivery, Vol. 26, No. 1, 2011, pp. 242-249.

[11]. S.H. Ko, S. Lee, H. Dehbonei, and C. Nayar, "Application of voltage and current-controlled voltage source inverters for distributed generation systems", IEEE Transaction on Energy Conversion, Vol. 21, No. 3, 2006, pp. 782-792.

[12]. Barros, and J. Silva, "Multilevel optimal predictive dynamic voltage restorer", IEEE Transactions on Industrial Electronics, Vol. 57, No. 8, 2010, pp. $2747-2760$.

[13]. S.R. Kumar, and S.S. Nagaraju, "Power quality improvement using DSTATCOM and DVR", IEEE International Journal of Electrical and Power Engineering, Vol. 1, No. 3, 2007, 368-376.

[14]. M. Tumay, A. Teke, K.C. Bayindir, and M.U. Cuma, "Simulation and modeling of a dynamic voltage restorer", Electrical \& Electronics Engineering, 2006, pp. 1-5. 